\title{
Efetividade do tratamento odontológico preventivo em pacientes com fissuras labiopalatinas no ambulatório de odontopediatria do hospital geral de Cuiabá - MT
}

\author{
Effectiveness of preventive dental treatment in patients with cleft lip and palate in the pediatric \\ outpatient clinic of the general hospital in Cuiabá - MT
}

\author{
Thyago Munoz De Freitas $^{1^{*}} \bullet$, Ana Thereza Saboia Campos Neves ${ }^{2}$, Gabriela Schmidt de Freitas ${ }^{1} \bullet$, \\ Thayna Ellen de Sousa Alves Ferreira ${ }^{10}$
}

\begin{abstract}
${ }^{1}$ Hospital Geral e Maternidade de Cuiabá, Programa de Residência Multiprofissional em Saúde Hospitalar do PNE, Cuiabá, Mato Grosso, Brasil. ${ }^{2}$ Hospital Geral e Maternidade de Cuiabá, Setor de Odontologia, Programa de Fissuras Labiopalatinas, Cuiabá, Mato Grosso, Brasil. *Autor para correspondência: E-mail: thy.munoz@gmail.com
\end{abstract}

\begin{abstract}
Resumo: Introdução: A fissura Labiopalatina é uma das alterações craniofaciais mais comuns no mundo e o cuidado odontológico preventivo pode prevenir uma série complicações pré e pós operatórias nestes pacientes, além de impactar diretamente na qualidade de vida. Objetivo: Este trabalho visa avaliar a eficácia dos processos preventivos utilizados pela equipe odontológica na redução no índice de cárie de pacientes com fissuras labiopalatinas por meio de análise dos prontuários. Método: Trata-se de um estudo transversal retrospectivo, em que foram coletados dados dos prontuários dos pacientes com idade de 0 a 2 anos admitidos no ambulatório de Odontopediatria no ano de 2016 e acompanhados até o ano de 2018. Resultado: Comprovou-se prevalência do sexo masculino, maior número de desistências no ano de 2016, relacionado ao maior número de pacientes do interior do estado, verificou-se ainda a prevalência das fissuras do tipo transforame incisivo com $52,17 \%$ dos pacientes, além de melhora na frequência de higiene e redução no uso da mamadeira e um baixo índice de CEO-D. Conclusão: conclui-se que o Programa e o tratamento preventivo demonstraram-se eficazes na redução do índice de cárie na população estudada.
\end{abstract}

Palavras-chave: fenda labial, fenda palatina, cuidados preventivos.

\begin{abstract}
Introduction: Cleft lip and palate is one of the most common craniofacial changes in the world and preventive dental care can prevent a series of pre- and post-operative complications in these patients, in addition to directly impacting quality of life. Objective: This work aims to evaluate the effectiveness of the preventive processes used by the dental team in reducing the caries index of patients with cleft lip and palate by analyzing the medical records. Method: This is a retrospective cross-sectional study, in which data were collected from the medical records of patients aged 0 to 2 years admitted to the Pediatric Pediatric Outpatient Clinic in 2016 and followed up until 2018. Result: Prevalence was proven males, a higher number of dropouts in 2016, related to the greater number of patients in the interior of the state, there was also a prevalence of incisive transforamenal fissures with $52.17 \%$ of patients, in addition to an improvement in the frequency of hygiene and reduced bottle use and a low CEO-D index. Conclusion: it is concluded that the Program and preventive treatment proved to be effective in reducing the caries index in the studied population.
\end{abstract}

Keywords: cleft lip, cleft palate, preventive care.

\section{Introdução}

A Odontologia tem como finalidade preservar e manter a saúde bucal por meios de ações preventivas, tais como o diagnóstico precoce, e também a orientação e motivação da criança iniciando-se ainda enquanto bebê, como também dos responsáveis inibindo futuras situações de estresse, medo e ansiedade, promovendo a autoestima, além, do empoderamento, tirando o indivíduo da situação de receptor, tornando-o assim responsável pelas ações que geram o auto cuidado e promovem a saúde bucal de forma reflexiva (Bendo et al., 2011; Oliveira, 2017; Ferreira, 2012).

A Odontologia preventiva para bebês surgiu nos anos 80 com a recomendação dos primeiros atendimentos a bebês ainda nos primeiros 6 meses de vida, e vem mostrando-se uma conduta eficaz e de grande valia na prevenção de doenças orais na infância estendendo-se até a fase adulta (Oliveira, 2017, Lemos et al., 2011). 
As fissuras labiopalatinas são alterações craniofaciais, de etiologia complexa e multifatorial sendo de origem genética e ambiental, podendo vir acompanhada de outras malformações, síndromes ou de forma isolada. Ocorre nas primeiras semanas de vida intrauterina, durante a fusão dos tecidos embrionários responsáveis pela formação da face, acometendo cerca de 1 a cada 600 recém-nascidos no mundo (Krapels et al., 2006; Johnson, \& Little, 2008; Lima, 2011).

Os pacientes com fissuras constituem um grupo de risco para desenvolvimento de cárie dentária. Ações preventivas voltadas a essa população devem ser desenvolvidas e aplicadas ainda na primeira infância afim de evitar futuras complicações prévias e pós cirúrgicas como infecções e dores (Sá et al, 2014; Silva, 2015).

As alterações morfológicas na região da fissura, próprias da malformação ou ainda da reparação cirúrgica realizada no local podem levar a fibroses cicatriciais, fístulas cicatriciais e a respiração bucal, gerando medo da manipulação da ferida cirúrgica para higienização pelos responsáveis, propiciando acúmulo de biofilme no local. Há ainda a dificuldade de sucção do leite materno levando o bebê à fadiga sem saciar a fome, promovendo o contato precoce com a mamadeira e seu conteúdo geralmente enriquecido de açúcares (Moura et al., 2009; Muncinelli et al., 2009).

Um outro fator a se considerar é a desinformação e a fragilidade emocional que pais ou responsáveis apresentam referente a necessidade e a técnica correta de higienização, deixando falho esse processo crucial na manutenção da saúde bucal. O choque emocional e familiar é muito grande levando os responsáveis a priorizarem neste momento as correções cirúrgicas, e com o decorrer do tempo essa preocupação se direciona a dificuldade da fala e à estética dental e funcional levando-os a priorizarem a procura pela ortodontia, deixando em último plano a higiene oral, que somada a uma dieta rica em açúcares e carboidratos e ao receio de manipulação da região da fissura ou falta de conhecimento dos responsáveis, leva ao aumento na ocorrência de cárie (Moura et al., 2013; Silva, 2015).

Essa tendência a cárie dentária pode ser revertida por meio de práticas preventivas diretas como visitas periódicas ao dentista, onde devem ser realizadas profilaxias profissionais com pasta profilática e aplicações de tópicas de flúor, e por práticas indiretas como educação aos pais e responsáveis como também das crianças (Moura et al., 2013; Silva, 2015).

\section{Materiais e métodos}

Trata-se de um estudo transversal retrospectivo, realizado no ambulatório de Odontopediatria do Serviço de Reabilitação de Fissuras Labiopalatinas do Hospital Geral, hospital referência no estado de Mato Grosso em patologias neurológicas, cardiorrespiratórias, malformações congênitas e craniofaciais, e maternidade. O projeto de pesquisa foi submetido ao Comitê de Ética em Pesquisa (CEP) da Universidade de Cuiabá, e aprovado sob o número 17889419.9.0000.5165

Foram coletados dados dos prontuários dos pacientes com idade de 0 a 2 anos admitidos no ambulatório de Odontopediatria no ano de 2016 e acompanhados até o ano de 2018. O período de coleta foi de dezembro de 2019 a janeiro de 2020, a saber: idade, sexo, classificação da fissura, frequência de higiene oral, uso de mamadeira, frequência no programa por ano e o índice CEO-D (dentes cariados, com extração indicada e obturados) dos pacientes que persistiram dentro do período proposto, no início e no fim do programa.

Os critérios de inclusão para esse estudo foram todos os pacientes que aderiram ao programa no ano de 2016 com idade entre 0 a 2 anos com fissura labiopalatina e que tiveram acompanhamento anual até $\mathrm{o}$ ano de 2018.

Foram excluídos do estudo pacientes que entraram no programa com idade superior a 2 anos de vida, e os que possuam alguma síndrome associada a fissura.

Dos 41 prontuários que passaram por uma primeira consulta no ambulatório de Odontopediatria no ano de 2016, 27 pacientes apresentavam fissura e 14 pacientes não a apresentavam. Dos 27 pacientes que apresentavam fissura, 4 foram excluídos por terem síndromes associadas, restando 23 prontuários de pacientes com fissuras labiopalatinas. Destes 23 prontuários, 10 foram excluídos por não realizarem o acompanhamento de forma contínua durante os anos propostos, restando uma amostra final de 13 prontuários de pacientes com fissura.

\section{Resultados}

Os dados dos 37 pacientes foram tabulados e calculados em porcentagens, sendo distribuídos de acordo com o ano, presença de fissura e continuidade no programa, onde foi observado que o maior número de pacientes atendidos no ambulatório de Odontopediatria possuíam fissuras labiopalatinas. Vale ainda relatar que os alguns pacientes abandonaram o programa no ano de 2016 e retomaram no ano 2018, conforme mostrado na tabela 1 abaixo. 
Tabela 1. Número de pacientes por ano.

\begin{tabular}{cccc}
\hline Total & $\mathbf{2 0 1 6}$ & $\mathbf{2 0 1 7}$ & $\mathbf{2 0 1 8}$ \\
& 37 & 26 & 21 \\
& $100 \%$ & $63,41 \%$ & $51,21 \%$ \\
\hline Fissuras Total & 2016 & $\mathbf{2 0 1 7}$ & $\mathbf{2 0 1 8}$ \\
\hline & 23 & 16 & 15 \\
\hline Sem Fissuras Total & $100 \%$ & $69,56 \%$ & $65,21 \%$ \\
\hline & 2016 & $\mathbf{2 0 1 7}$ & $\mathbf{2 0 1 8}$ \\
\hline & 14 & 9 & 6 \\
\hline
\end{tabular}

Os pacientes que desistiram do programa foram classificados em porcentagem de acordo com o ano da desistência, onde constatamos maior número de desistências no ano de 2016 com grande quantidade delas após a primeira consulta, enquanto outros chegaram a ter três consultas no ano de 2016 porém não retornando ao serviço no ano de 2017, com maior percentual nos pacientes com fissuras. Já no ano de 2017 os percentuais de desistências foram iguais em ambos os grupos conforme a tabela 2 abaixo.

Tabela 2. Desistentes.

\begin{tabular}{ccc}
\hline Total & Fissuras & Sem Fissuras \\
\hline $\mathbf{2 0 1 6}$ & $\mathbf{2 0 1 6}$ & $\mathbf{2 0 1 6}$ \\
\hline 15 & 7 & 6 \\
$65,21 \%$ & $30,43 \%$ & $26,08 \%$ \\
\hline $\mathbf{2 0 1 7}$ & $\mathbf{2 0 1 7}$ & $\mathbf{2 0 1 7}$ \\
\hline 8 & 3 & 3 \\
& $13,04 \%$ & $13,04 \%$ \\
\hline
\end{tabular}

Nos resultados obtidos na análise descritiva identificou-se com relação ao sexo no total de pacientes com fissuras que entraram no programa em 2016, 14 (60,86\%) eram do sexo masculino e $9(39,19 \%)$ do sexo feminino. Dos 13 pacientes com fissura que permaneceram e foram atendidos no programa em 2016, 2017 e 2018, 9 pacientes $(69,20 \%)$ eram do sexo masculino e 4 eram do sexo feminino (30,70\%), demostrando prevalência do sexo masculino nos pacientes com fissuras labiopalatinas em ambos os grupos. Já nos pacientes sem fissuras a predominância foi do sexo feminino com 8 pacientes $(57,14 \%)$, conforme demonstra a Figura 1.

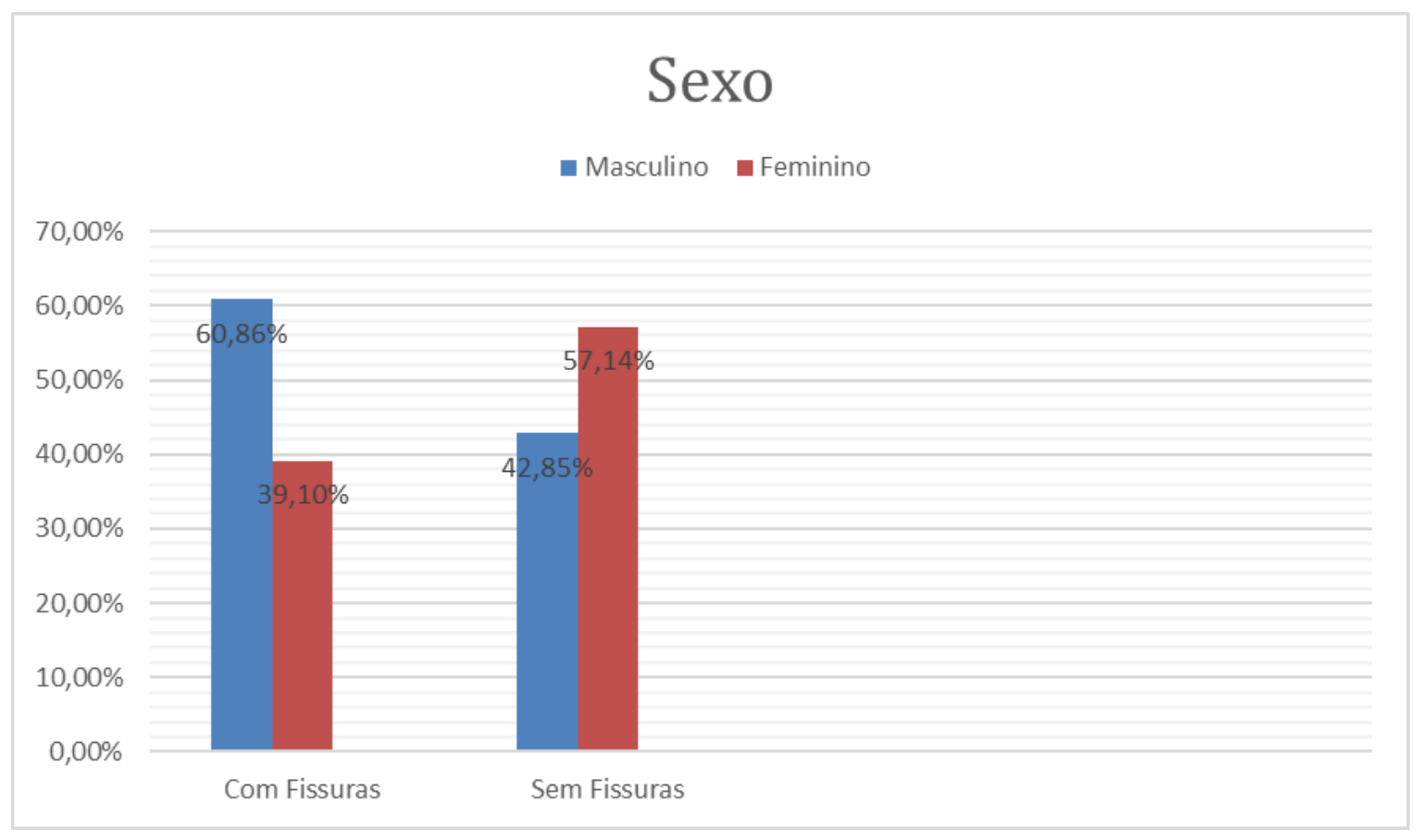

Figura 1. Presença e ausência de fissuras quanto ao sexo.

Em relação a idade foi calculado a média em meses na primeira consulta realizada no ano de 2016 onde obteve-se a média de 6,30, e da última consulta realizada no ano de 2018 onde foi encontrada a média de 
33,69, nos pacientes com fissuras conforme a tabela 3. Foi ainda realizado um cálculo de média com relação ao número de consultas totais dos pacientes com fissura que receberam atendimento contínuo nos anos de 2016, 2017 e 2018 onde o número médio de consultas atingiu 6,30, sendo que no ano de 2016 obteve-se uma média de consultas maior que nos anos de 2017 e 2018, conforme demonstrado na tabela 4 .

Tabela 3. Média de idade em meses.

\begin{tabular}{cccc}
\hline Consulta Fissuras & Total Pacientes & Média Inicial & Média Final \\
\hline Consulta Sem Fissuras & 13 & Média: 6,30 & Média: 33,69 \\
\hline & & & \\
\hline
\end{tabular}

Tabela 4. Médias de consultas.

\begin{tabular}{ccccc}
\hline Fissuras Total & Total & $\mathbf{2 0 1 6}$ & $\mathbf{2 0 1 7}$ & $\mathbf{2 0 1 8}$ \\
& Média: 4,65 & Média: 1,91 & Média: 1,30 & Média: 1,43 \\
\hline Sem Fissuras Total & Total & $\mathbf{2 0 1 6}$ & $\mathbf{2 0 1 7}$ & $\mathbf{2 0 1 8}$ \\
& Média: 3,78 & Média: 1,5 & Média: 1,42 & Média: 0,85 \\
\hline Fissuras Contínuo & Total & $\mathbf{2 0 1 6}$ & $\mathbf{2 0 1 7}$ & $\mathbf{2 0 1 8}$ \\
& Média: 6,30 & Média: 2,07 & Média: 1,92 & Média: 1,76 \\
\hline $\begin{array}{c}\text { Sem Fissuras } \\
\text { Contínuo }\end{array}$ & Total & $\mathbf{2 0 1 6}$ & $\mathbf{2 0 1 7}$ & $\mathbf{2 0 1 8}$ \\
& & & Média: 2,8 & Média: 2 \\
\hline
\end{tabular}

Quanto aos municípios de origem dos pacientes com fissura, estes foram divididos em Capital, Interior e Outro Estado, onde obtivemos o seguinte resultado respectivamente, 7 (30,43\%), 15 (65,21\%) e 1 (2,43\%), demonstrando um percentual significante de pacientes do interior do estado nesse grupo. Quanto aos pacientes que não possuíam fissura o maior número de pacientes era proveniente da capital, conforme a figura 2 .

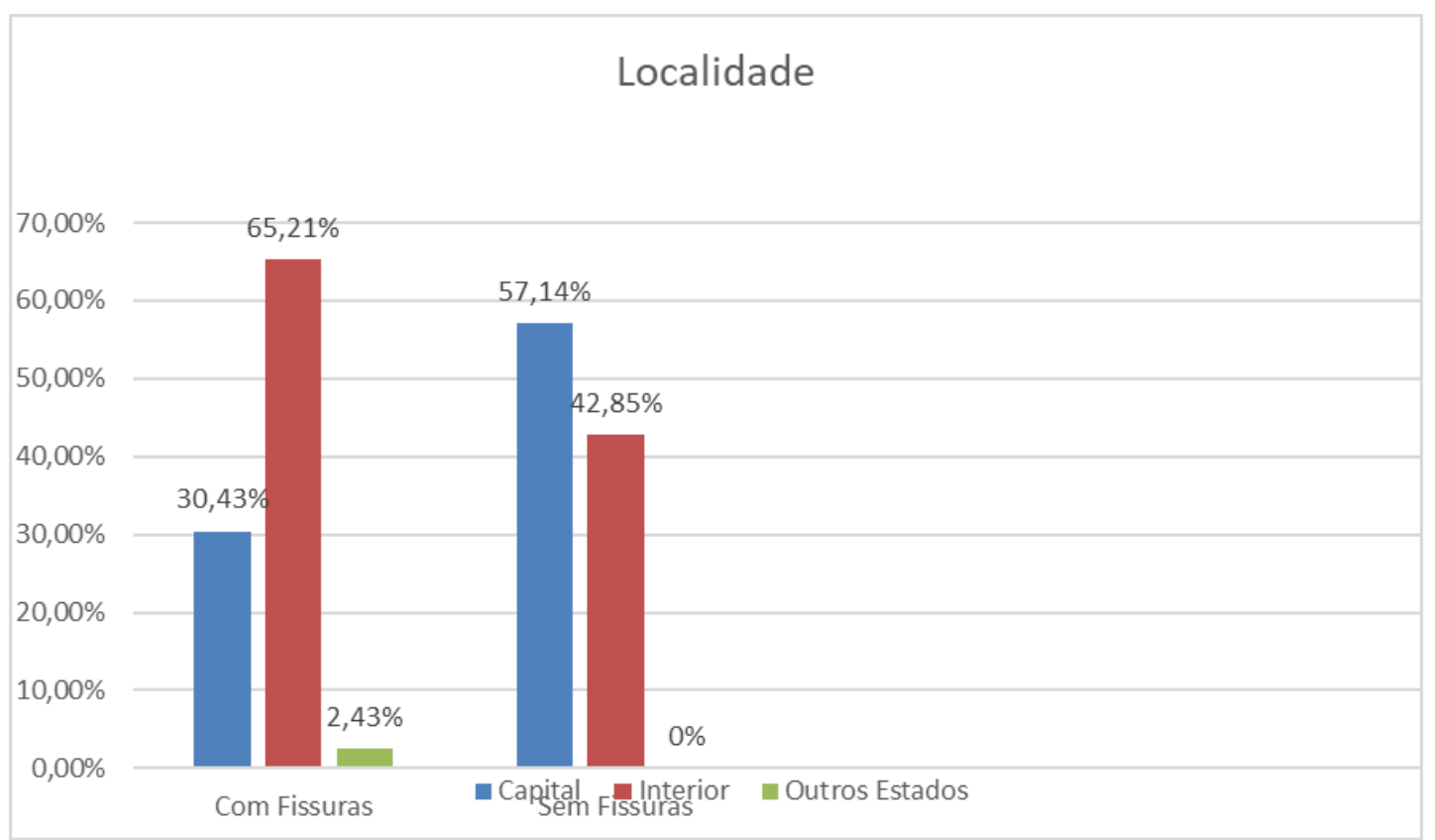

Figura 2. Presença e ausência de fissuras quanto ao local de habitação.

Em relação à frequência de higiene bucal, o cálculo também foi realizado em média de acordo com a primeira consulta de 2016 e a última consulta de 2018 , considerando a frequência diária de higiene, indo de 0 a 3 vezes ao dia, constatando-se um aumento expressivo na frequência de higiene após o tempo de programa com maior média no ano de 2018 conforme demonstra a tabela 5. Para avaliar o uso da mamadeira foi utilizado a palavra SIM, para os pacientes que estavam em uso da mamadeira e não para os pacientes que não utilizaram ou pararam de utilizar no decorrer do período de estudo. Posteriormente foram divididos em dois grupos e avaliados em porcentagem, onde no primeiro grupo foi avaliado o uso da mamadeira durante a primeira consulta no ano de 2016, e no segundo grupo foi avaliado o uso da mamadeira na última consulta do ano de 2018, demonstrando uma brusca redução deste hábito deletério indo de 100\% em 2016 para 23,07\% em 2018 nos pacientes com fissura. 
Tabela 5. Relação entre a higiene e o uso de mamadeira.

\begin{tabular}{ccccc|cccc}
\hline & \multicolumn{3}{c}{ Higiene bucal } & \multicolumn{4}{c}{ Uso de mamadeira } \\
\hline & $\begin{array}{c}\text { Total } \\
\text { Pacientes } \\
2016\end{array}$ & $\begin{array}{c}\text { Média } \\
\text { inicial } \\
\%\end{array}$ & $\begin{array}{c}\text { Após } 24 \\
\text { meses }\end{array}$ & $\begin{array}{c}\text { Média } \\
\text { Final } \\
\%\end{array}$ & $\begin{array}{c}\text { Total } \\
\text { Pacientes } \\
2016\end{array}$ & $\begin{array}{c}\text { \% inicial } \\
24\end{array}$ & $\begin{array}{c}\text { Após } \\
\text { Meses }\end{array}$ \\
\hline $\begin{array}{c}\text { Com } \\
\text { Fissuras }\end{array}$ & 13 & 0,84 & 13 & 2,76 & 13 & $100 \%$ & 13 & $23,07 \%$ \\
\hline $\begin{array}{c}\text { Sem } \\
\text { Fissuras }\end{array}$ & 5 & 0,8 & 5 & 2,2 & 5 & $60 \%$ & 5 & $20 \%$ \\
\hline
\end{tabular}

Os dados do índice de CEOD, foram dispostos de acordo com a média da primeira consulta de 2016 e de acordo com a média da última consulta de 2018. Neste índice, as manchas brancas não foram contabilizadas como cárie durante a coleta dos dados. Sendo assim foi encontrado o índice 0 no ano de 2016 considerando que os pacientes ainda não possuíam elementos dentários erupcionados na cavidade bucal. Já no ano de 2018 a média de CEOD foi de 1,07, demonstrando a eficácia no tratamento preventivo proposto no programa conforme demonstrado na tabela 6.

Tabela 6. Média de CEO-D.

\begin{tabular}{cccc}
\hline Com Fissura & Total pacientes & Média Inicial & Média Final \\
\hline & 13 & Média:0 & Média: 1,07 \\
\hline Sem Fissura & Total Pacientes & Média Inicial & Média Final \\
\hline & 5 & Média:0 & Média:0 \\
\hline
\end{tabular}

Para a classificação das fissuras foi utilizada a classificação de Spina (1972), além do cálculo em porcentagens onde verificou-se a prevalência das fissuras do tipo transforame incisivo com $52,17 \%$ dos pacientes, seguida das fissuras pré-forame incisivo completas com $26,08 \%$ como demonstra a figura 3 abaixo.

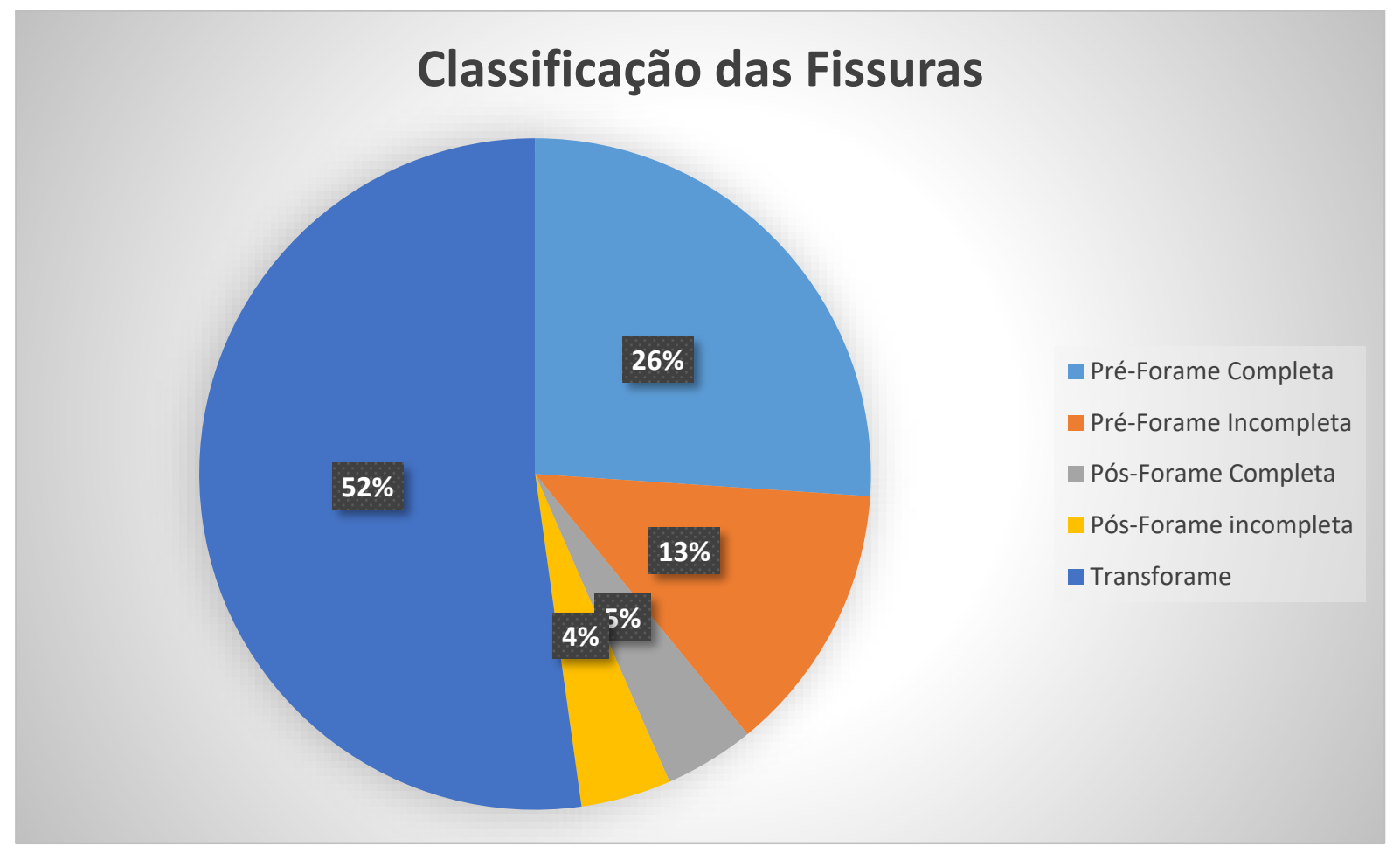

Figura 3. Distribuição conforme a classificação das fissuras.

\section{Discussão}

O Hospital Geral e Maternidade de Cuiabá, constitui um centro de cuidados com vários serviços de referência, tal como o de malformações congênitas e craniofaciais, onde se enquadra o Serviço de Reabilitação de Fissuras Labiopalatinas. Este serviço constitui em um núcleo multiprofissional voltado aos cuidados, a 
integralidade e reabilitação do indivíduo com fissura labiopalatina, e conta com profissionais de diversas áreas como Médicos Pediatras, Otorrinolaringologistas, Cirurgiões Plásticos, além de Psicólogos, Fonoaudiólogos, Nutricionistas, Fisioterapeutas, Odontopediatras, Cirurgiões Bucomaxilofaciais e Ortodontistas.

Atualmente o serviço atende cerca de 1100 pacientes, com maior concentração de pacientes do Estado de Mato Grosso, tendo recebido um total de 55 novos pacientes apenas no ano de 2016.

Dentro dos cuidados oferecidos aos pacientes com fissuras labiopalatinas encontram-se os serviços de tratamento preventivo e restaurador ofertados pelo ambulatório de Odontopediatria que procura promover saúde bucal, e restabelecer a mesma previamente à correção cirúrgica e mantê-la no pós-operatório por meio de ações educativas aos responsáveis e motivacionais e preventivas aos pacientes para que obtenham a capacidade de realizar a própria higiene por meio da técnica apropriada, além do uso de flúor e na orientação de uma dieta adequada.

Dos 55 novos pacientes recebidos no programa de fissuras no ano de 2016, 31 destes pacientes entraram no Serviço de Fissuras do Hospital Geral com menos de 2 anos de idade, e dos 31 que entraram com menos de 2 anos, 23 receberam em 2016 a primeira consulta no ambulatório de Odontopediatria.

A fissura labiopalatina é uma má formação craniofacial de grande incidência acometendo cerca de 1 para cada 650 nascimentos, e que traz uma série de consequências físicas e psicossociais ao indivíduo acometido e aos seus familiares, sendo que as fissuras transforame incisivo são as mais prevalentes como evidenciado neste estudo (Silva et al., 2008; Kuhn et al., 2012). As alterações afetam a face comprometendo a estética e o funcional do paciente. Estudos epidemiológicos realizados no Brasil demonstram que há uma prevalência maior no sexo masculino como comprovam Cymrot et al. (2010) e Freitas et al. (2013), corroborando os achados nos resultados deste trabalho.

O estado de Mato Grosso tem a extensão de $903.206,997 \mathrm{~km}^{2}$, sendo um dos maiores estados do país, contando com 141 municípios, sendo a capital o município de Cuiabá. O Serviço de Reabilitação de Fissuras do Hospital Geral e Maternidade de Cuiabá atende todo estado, conforme demonstram os resultados, no ano de 2016 a maioria dos atendimentos foram dos pacientes do interior do estado, contando com $65,21 \%$, o que pode estar diretamente ligado com os fatores causais ambientais, tais como fatores socioeconômico, saneamento básico, exposição a agrotóxicos entre outros, conforme apontam Raposo-Do-Amaral et al. (2011) e Costa et al. (2013). Este fato pode estar diretamente ligado com o número de desistências do programa, visto que $60 \%$ dos desistentes eram do interior do estado, com maiores desistências no primeiro ano de atendimento. Isto ocorre devido a distância entre os municípios e a capital podendo atingir 1000 quilômetros ou mais, demonstrando assim a necessidade de investimentos na capacitação de profissionais e estruturas a nível municipal para o atendimento destes pacientes, promovendo saúde integral e qualidade de vida.

As alterações morfológicas na região da fissura, podem levar ao medo da manipulação da área da fissura para higienização pelos responsáveis, propiciando acúmulo de biofilme no local. Há ainda o contato precoce com a mamadeira e seu conteúdo geralmente enriquecido de açúcares sendo estes fatores cariogênicos. Partindo disto, ações preventivas e educativas, tais como orientação e motivação de higiene bucal e dieta especialmente quanto ao uso de mamadeira com conteúdo enriquecido de açúcar, higiene bucal supervisionada, profilaxia com pasta profilática, e aplicações tópicas de flúor gel, são realizadas dentro do ambulatório de Odontopediatria do Hospital Geral nos pacientes assistidos pelo programa a cada 3 meses, com o intuito de proporcionar uma educação continuada e prevenir complicações peri e pós-operatórias, nas correções cirúrgicas as quais esses pacientes serão submetidos. Nos pacientes atendidos no programa de 2016 até 2018, estas orientações se mostraram efetivas constatando-se uma redução significativa no uso de mamadeira e o aumento na frequência de higiene, estes achados se mostram alcançáveis devido a intervenção precoce e continuada, com ações educativas individualizadas na primeira infância, como o público alvo deste estudo com média inicial de idade de 6,30 meses de idade, como comprova Zuanon et al. (2004), Kuhn e Wambier (2006) e Fernandes e Dafini (2013).

Sendo assim, a intervenção precoce somada as condutas de motivação e orientação para os pacientes e responsáveis é de fundamental importância para manutenção da saúde bucal destes pacientes, prevenindo doenças orais tais como a cárie, conforme o encontrado na análise do índice de CEO-D, onde a média inicial e final de 0 nos pacientes sem fissuras e uma média inicial de 0 e final de 1,07 nos pacientes com fissuras, alcançando $76,92 \%$ dos pacientes com fissuras livres de cárie, que quando comparado aos dados da Secretaria de Vigilância em Saúde, com média de CEOD de 3,17 em crianças com até cinco anos do estado de Mato Grosso no ano de 2010,comprova a eficiência do atendimento precoce prestado no ambulatório de Odontopediatria do Hospital Geral e Maternidade de Cuiabá no atendimento aos pacientes com fissuras labiopalatinas (Brasil, 2010). 


\section{Conclusão}

Desta forma conclui-se que houve eficácia do programa preventivo como demonstrado por meio da média encontrada no índice de CEO-D, e que existe a necessidade de capacitação de profissionais e formação estrutural para ampliar o atendimento regional a esses pacientes, diminuindo o número de desistências no acompanhamento educativo e preventivo contínuo ainda na primeira infância.

\section{Referências}

Bendo, C. B., Viegas, C. M. Sardenberg, F., Zarzar, P. M. P. A., Vale, M. P., \& Paiva, S. M. 2011. Programa de promoção da saúde em Odontopediatria - Arq Odontol, 47(Supl 2), 42-44.

Brasil. 2010. Secretaria de Atenção à Saúde. Secretaria de Vigilância em Saúde. Pesquisa Nacional de Saúde Bucal: resultados principais / Ministério da Saúde. Secretaria de Atenção à Saúde. Secretaria de Vigilância em Saúde. Brasília, DF: Ministério da Saúde.

Costa, R. R., Takeshita, W. M., \& Farah, G. J. 2013. Levantamento epidemiológico de fissuras labiopalatais no município de Maringá e região. Revista da Associacao Paulista de Cirurgioes Dentistas, 67(1), 40-4.

Cymrot, M., Sales, F. C. D., Teixeira, F. A. A., Junior, F. A. A. T., Teixeira, G. S. B., Filho, J. F. C., \& Oliveira, N. H. 2010. Prevalência dos tipos de fissura em pacientes com fissuras labiopalatinas atendidos em um Hospital Pediátrico do Nordeste brasileiro. Revista Brasileira de Cirurgia Plástica, 25(4), 648-651.

Fernandes, R., \& Defani, M. A. 2013. Importância da Equipe Multidisciplinar no Tratamento e Proservação de Fissuras Labiopalatinas. Saúde e Pesquisa, 6(1), 109-116.

Ferreira, M. A. F. 2012. Odontologia preventiva na primeira infância: uma alternativa para se evitar medo e ansiedade relacionados ao tratamento odontológico -Trabalho de Conclusão de Curso em especialização em atenção básica e saúde da família. Corinto, MG.

Freitas, M. C. A., Batista, T. S., Pereira, M. C. G., Brandão, M. M., Marianetti, L. V. S., \& Almeida, P. P. 2013. Estudo epidemiológico das fissuras labiopalatinas na Bahia. Revista UNINGÁ, 37, 13-22.

Johnson, C. Y., \& Little, J. 2008. Folate intake, markers of folate status and oral clefts: is the evidence converging?. International journal of epidemiology, 37(5), 1041-1058.

Krapels, I. P.C., Zielhuis, G. A., Vroom, F., Jong-van den berg, L. T.W., Kuijpers-jagtman, A-M, Van der molen, A. B. M., \& Steegers-theunissen, R. P.M. 2006. Periconceptional Health and Lifestyle Factors of Both Parents Affect the Risk of Live-Born Children with Orofacial Clefts. Birth Defects Research (Part A) 76, 613620.

Kuhn, E., \& Wambier, D. S. 2007. Incidência de lesões de cárie em bebês após 15 meses de um programa educativo-preventivo. Pesquisa Brasileira em Odontopediatria e Clínica Integrada, 7(1), 75-81.

Kuhn, V. D., Miranda, C., Dalpian, D. M., Moraes, C. M. B., Backes D. S., Martins, J. S., \& Santos, B. Z. 2012. Fissuras labiopalatais: revisão de literatura. Disciplinarum Scientia. Série: Ciências da Saúde, 13(2), 237-245.

Lemos, L. V. F. M., Zuanon, A. C. C; Myaki, S. I., \& Walter, L. R. F. 2011. Experiência de cárie dentária em crianças atendidas em um programa de Odontologia para bebês. Einstein, 9(4), 503-7.

Lima, W. G. 2011. Prevalência de fissuras labiopalatais em maternidade municipal de Campina Grande - PB no período de cinco anos. Trabalho de Conclusão de Curso, Faculdade de Odontologia, Universidade Estadual da Paraíba, Centro de ciências biológicas e da Saúde. Campina Grande, PB: UEPB.

Moura, A. M., Andre, M., Faraj, J. O. R. A., \& Brito e Dias, R. 2009. Avaliação de bebês portadores de fissura labiopalatina em relação à higiene oral. Revista Odonto, 17(34).

Moura, A. M., Paiva, T. B. S., Lopez M. T., \& André, M. 2013. Prevalência de cárie em crianças portadoras de fissura labiopalatal. Odonto, 21(41-42), 55-63.

Muncinelli, E. A. G., Oliveira, G. H. C., Esper, L. A., \& Almeida, A. L. P. F. 2012. Aspectos periodontais em pacientes com fissuras labiop alatinas. PerioNews;6(4), 359-63.

Oliveira, I, S. 2017. Assistência odontológica educativa-preventiva para bebês. Trabalho de Conclusão de Curso, Faculdade de Odontologia: Universidade Estadual Paulista Júlio de Mesquita Filho - Araçatuba, SP: UNESP.

Raposo-do-Amaral, C. E., Kuczynski, E., \& Alonso, N. (2011). Qualidade de vida de crianças com fissura labiopalatina: análise crítica dos instrumentos de mensuração. Revista Brasileira de Cirurgia Plástica, 26(4), 639-644. 
Sá, J. O., Maranhão, S. C., Canguçú, D. L., Coutinho, T. S. L., Medrado, A. P., \& Reis, S. R. A. 2014. Anomalias dentárias nas fissuras labiais e/ou palatinas não-sindrômicas. Revista Bahiana de Odontologia, 5(3):153159.

Silva, D. S. F., Mauro, L. D. L., Oliveira, L. B., Ardenghi, T. M., \& Bönecker M. 2008. Estudo descritivo de fissuras lábio-palatinas relacionadas a fatores individuais, sistêmicos e sociais- $R G O, 56(4), 387-391$.

Silva, T. R. 2015. Prevalência de cárie em bebês com fissuras labiopalatinas e sua correlação com fatores socioeconômicos e hábitos de higiene bucal. Trabalho de Conclusão de Doutorado, Hospital de reabilitação de anomalias craniofaciais, Universidade de São Paulo. Bauru, SP: USP.

Zuanon, Â. C. C., Campos, J. Á. D. B., Azevedo, E., Domaneschi, C., \& Menezes, T. M. 2004. Atendimento odontológico precoce-estudo longitudinal. Revista Ciência em Extensão, 1(2), 130-136.

\section{Minicurrículo}

Thyago Munoz De Freitas. Graduado em Odontologia pela Universidade de Cuiabá - UNIC. Residência Multiprofissional em Saúde Hospitalar do PNE no Hospital Geral e Maternidade Cuiabá/MT - HG. PósGraduado em Docência do Ensino Superior pela Faculdade de São Vicente -FSV. Mestrando em Saúde Coletiva pela Universidade Federal do Mato Grosso - UFMT.

Ana Thereza Saboia Campos Neves. Graduação em Odontologia pela Universidade Gama Filho - UGF. Especialista em Odontopediatria pela Universidade de São Paulo - USP. Mestre e Doutora em Ciências Odontológicas Integradas pela Universidade de Cuiabá - UNIC.

Gabriela Schmidt de Freitas. Graduação em Odontologia pela Universidade de Cuiabá - UNIC. Residente na Residência Multiprofissional em Saúde Hospitalar do PNE no Hospital Geral e Maternidade Cuiabá/MT - HG.

Thayna Ellen de Sousa Alves Ferreira. Graduação em Odontologia pela Universidade de Cuiabá - UNIC Residente na Residência Multiprofissional em Saúde Hospitalar do PNE no Hospital Geral e Maternidade Cuiabá/MT - HG.

Como citar: Freitas, T.M., Neves, A.T.S.C., Freitas, G.S., \& Ferreira, T.E.S.A. 2020. Efetividade do tratamento odontológico preventivo em pacientes com fissuras labiopalatinas no ambulatório de odontopediatria do hospital geral de Cuiabá - MT. Pubsaúde, 4, a054. DOI: https://dx.doi.org/10.31533/pubsaude4.a054

Recebido: 16 jul. 2020.

Revisado e aceito: 26 jul. 2020.

Conflito de interesse: os autores declaram, em relação aos produtos e companhias descritos nesse artigo, não ter interesses associativos, comerciais, de propriedade ou financeiros que representem conflito de interesse.

Licenciamento: Este artigo é publicado na modalidade Acesso Aberto sob a licença Creative Commons Atribuição 4.0 (CC-BY 4.0). 